\title{
Avaliação da atividade antifúngica de extratos fenólicos de cebola, farelo de arroz e microalga Chlorella phyrenoidosa
}

\author{
Antifungal activity evaluation in phenolic extracts from onion, rice bran, and Chlorella phyrenoidosa
}

\author{
Michele Moraes de SOUZA ${ }^{1 *}$, Melissa dos Santos OLIVEIRA ${ }^{1}$, Meritaine da ROCHA $^{1}$, Eliana Badiale FURLONG ${ }^{1}$
}

\begin{abstract}
Resumo
O objetivo deste trabalho foi relacionar os níveis de fenóis totais em cebola, farelo de arroz e microalga Chlorella phyrenoidosa com a atividade antifúngica testada contra o fungo Rhyzopus oryzae. Os compostos fenólicos da cebola foram extraídos em três sistemas solventes: aquoso, metanólico e com acetato de etila, os do farelo de arroz e da microalga Chlorella phyrenoidosa extraídos com metanol. Os extratos foram quantificados colorimetricamente com reagente de Folin-Ciocalteau. O método para avaliar a atividade antifúngica empregou a técnica de Ágar diluído. O Rhyzopus oryzae teve seu desenvolvimento inibido em presença de extratos metanólico e acetoetílicos de cebola e metanólico de farelo de arroz, que continham as concentrações de compostos fenólicos testadas, 86; 2,6; e $46 \mu \mathrm{g}_{\text {fenóis }} \cdot \mathrm{mL}^{-1}{ }_{\text {meio }}$, respectivamente. O extrato aquoso de cebola e metanólico de Chlorella phyrenoidosa não inibiram o crescimento fúngico em nenhuma das concentrações fenólicas testadas.
\end{abstract}

Palavras-chave: atividade antifúngica; fenóis; extratos vegetais.

\begin{abstract}
The objective of this work was to relate the levels of total phenolic in onion, rice bran, and Chlorella phyrenoidosa with the antifungal activity tested against the fungus Rhyzopus oryzae. The phenolic compounds of onion were extracted in three solvent systems: aqueous, methanolic, and with ethila acetate, whereas the phenolic compounds of rice bran and Chlorella phyrenoidosa were extracted with methanol. The extracts were quantified with the Folin-Ciocalteau reagent. The method to evaluate the antifungal activity employed was the diluted Ágar technique. The Rhyzopus oryzae had its development inhibited in the presence of onion methanolic and aceto-ethylic extracts and rice bran methanolic extracts at the following phenolic concentrations, $86 ; 2.6$, and $46 \mu \mathrm{g}_{\text {phenolic }} \cdot \mathrm{mL}^{-1}$ agar respectively. The aqueous extracts from onion and the methanolic extract from Chlorella phyrenoidosa did not inhibit fungal growth under the phenolic concentrations tested.

Keywords: antifungal activity; phenolic; vegetable extracts.
\end{abstract}

\section{Introdução}

Os compostos fenólicos (ferúlico, cinâmico e vanílico) presentes em tecidos vegetais possuem efeitos inibitórios no crescimento de fungos e produção de micotoxinas. Os ácidos $\rho$-hidroxibenzoico, vanílico e protocatequínico são inibidores somente em concentrações relativamente altas. O metil éster ácido cisferúlico e o metil éster ácido cis-3,4-dimetoxicinâmico, derivados do ácido cinâmico, são inibidores em pequenas concentrações, na faixa de 1 a $10 \mathrm{nM}$, evidenciando que a atividade inibitória depende não só da concentração, mas também da estrutura do composto (BAKAN et al., 2003; GRIFFIN, 1994; RASOOLI; ABYANEH, 2004). Estas demonstrações sugerem uma perspectiva de substituir aditivos químicos por conservadores naturais obtidos destas estruturas vegetais (BRULL; KLIS, 1999), o que atenderia à atual demanda de produção de alimentos seguros e implementaria o uso de porções vegetais usualmente descartadas (MELO; GUERRA, 2002).

Para a extração dos compostos fenólicos de raízes, tubérculos, frutas, espécies dos gêneros de Acácia, Terminália, Copernicia, maçãs, ameixas e outros, vêm sendo usados sistemas aquosos, alcoólicos e acetoetílicos sob diferentes condições de interação (LIMA et al., 2004; SOUSA et al., 2007). A quantificação dos compostos fenólicos totais nos diferentes extratos tem empregado o reagente de Folin-Ciocalteau.

Para o contexto da agroindústria da região Sul do Brasil, seria interessante conhecer o potencial de resíduos de cebola e de coprodutos de arroz como fonte de conservadores naturais para extração e utilização na preservação natural de alimentos, pois permitiria a valorização de matérias-primas e coprodutos de baixo valor comercial. No entanto, a atividade antifúngica, que vem sendo atribuída a compostos fenólicos usualmente presentes em tecidos destes vegetais, não tem sido estudada nestes recursos agrícolas.

Apesar do conhecimento milenar dos benefícios da cebola, demonstrados em diversos estudos sobre seus efeitos bioativos, algumas regiões produtoras têm dificuldades em comercializar suas safras em condições satisfatórias para consumo in natura ou em formulações industriais, resultando em descarte de material e desestímulo aos produtores (EMATER, 2007). 
Em levantamento realizado pela CONAB em 2007, a produção brasileira de arroz na safra de 2006/2007 chegou a 11,94 milhões de toneladas de produto beneficiado, resultando em aproximadamente 1,2 milhão de tonelada de farelo, que, por suas características sensoriais e pela disponibilidade discutível de nutrientes, é comercializada a valores pouco compensadores para o setor industrial (CONAB, 2008).

A microalga Chlorella phyrenoidosa tem diferentes ações biológicas identificadas, mas as suas propriedades como conservadora são pouco exploradas (DERNER et al., 2006). Considerando-se que os recursos hídricos naturais da região Sul do Rio Grande do Sul são adequados para o cultivo da microalga, a demonstração deste potencial poderá vir a ser mais um subsídio para a implementação do cultivo de Chlorella em larga escala no ecossistema costeiro local.

Esses aspectos nortearam o trabalho que objetivou determinar o conteúdo de compostos fenólicos totais em cebola, farelo de arroz e microalga Chlorella phyrenoidosa, relacionando-os com a atividade antifúngica testada contra o fungo Rhyzopus oryzae, utilizando o método de Ágar diluído.

\section{Material e métodos}

\subsection{Matérias-primas}

As cebolas foram coletadas no município de São José do Norte, no Rio Grande do Sul, em março de 2007, classificadas segundo Regulamento Técnico de qualidade da cebola (1995) do Ministério da Agricultura, Pecuária e Abastecimento (MAPA), pelos técnicos da EMATER - RS. O farelo de arroz foi obtido de grãos da variedade BR - IRGA 417 cultivados em campos experimentais do Instituto Riograndense do Arroz (IRGA) e para as determinações foi moído até granulometria de $0,355 \mathrm{~mm}$. A microalga Chlorella phyrenoidosa foi obtida na forma de pastilhas em lojas especializadas em produtos naturais na cidade de Rio Grande - RS e foram pulverizadas para o estudo.

\section{Caracterização físico-química das amostras}

O material vegetal foi homogeneizado em água previamente fervida na proporção de 1:9 sob agitação por 30 minutos. No sobrenadante, foi determinado o $\mathrm{pH}$ potenciometricamente, utilizando um pHmetro marca Hanna modelo 200; e a acidez por titulometria de neutralização com $\mathrm{NaOH} 0,1 \mathrm{~N}$, sendo expressa como porcentagem de ácido pirúvico (ASSOCIATION..., 2000).

A extração dos compostos fenólicos da cebola foi realizada a frio com água, acetato de etila e metanol na proporção de massa/ volume (m/v) 1:10. Os compostos fenólicos do farelo de arroz e da microalga Chlorella phyrenoidosa foram extraídos com metanol, nas proporções de 1:10 e 4:100 m/v, respectivamente. As extrações foram conduzidas em agitador horizontal sob temperatura ambiente, seguidas de partição com hexano, clarificação com hidróxido de bário $0,1 \mathrm{M}$ e sulfato de zinco $5 \%$ e filtração em papel de filtro whatman $n^{\circ} 4$. Os extratos foram secos em rotaevaporador e armazenados em freezer até quantificação e/ou posterior uso. O conteúdo de fenóis totais, das diferentes matrizes, foi determinado através do método espectrofotométrico de Folin-Ciocalteau, tendo como padrões a quercetina (2 a $\left.16 \mu \mathrm{g} \cdot \mathrm{ml}^{-1}\right)$, a tirosina $\left(2 \mathrm{a} 16 \mu \mathrm{g} \cdot \mathrm{ml}^{-1}\right)$, e o ácido ferúlico $\left(2\right.$ a $\left.16 \mu \mathrm{g} \cdot \mathrm{ml}^{-1}\right)$, respectivamente para a cebola, Chlorella phyrenoidosa e farelo de arroz (BADIALE-FURLONG et al., 2003; COLLA; BADIALE-FURLONG; COSTA, 2007).

\section{Avaliação da atividade antifúngica}

O fungo filamentoso utilizado neste estudo foi o Rhyzopus oryzae, cedido pelo Centro de Pesquisa em Alimentos da Universidade de Passo Fundo - UPF. Este foi mantido em Ágar Batata Dextrose (BDA) a $4{ }^{\circ} \mathrm{C}$ até o uso. A suspensão de esporos utilizada no teste antifúngico foi obtida pela propagação do fungo em meio BDA, após incubação por 10 dias a $30^{\circ} \mathrm{C}$, seguida de extração dos esporos do meio com solução $0,2 \%$ de Tween 80 , filtração e enumeração de esporos em câmara de Neubauer.

A atividade antifúngica foi determinada pelo método bioanalítico in vitro que consistiu em acompanhar o desenvolvimento dos microrganismos em placas contendo meio BDA na presença e ausência dos extratos fenólicos em teste. $\mathrm{O}$ meio de cultura foi preparado com os cuidados assépticos usuais em cultivo microbiano. Em cada placa foram adicionados os extratos fenólicos nas concentrações do estudo, sendo adicionados para o extrato metanólico de cebola, 70 a $86 \mu \mathrm{g}_{\text {fenóis }} \cdot \mathrm{mL}^{-1}$ meio ; extrato acetoetílico de cebola 2,0 a $2,3 \mu \mathrm{g}$ fenóis $\mathrm{mL}^{-1}$ meio ; extrato aquoso de cebola 120 a $185 \mu \mathrm{g}_{\text {fenóis }} \cdot \mathrm{mL}^{-1}$ meio ; para o farelo de arroz, 28 a $46 \mu \mathrm{g}_{\text {fenóis }} \cdot \mathrm{mL}^{-1}{ }_{\text {meio }}$; e para a Chlorella phyrenoidosa 3,0 a $3,7 \mu \mathrm{g}_{\text {fenóis }} \cdot \mathrm{mL}^{-1}{ }_{\text {meio }}$. Em seguida, foram acrescentados em todas as placas $20 \mathrm{~mL}$ do meio, homogeneizando para distribuir os extratos fenólicos no meio, sempre observando as condições assépticas (Câmara de Fluxo Laminar LABCONCO modelo 36210, tipo $B_{2}$ ). Nas placas controle, os extratos foram substituídos pela mesma quantidade de água estéril, adicionada antes do meio de cultura. Após a solidificação, foram adicionados ao centro das placas $5 \mu \mathrm{L}$ da solução de esporos contendo $1,6 \times 10^{7}$ esporos. $\mathrm{mL}^{-1}$. A incubação ocorreu em câmara de germinação modelo Tecnal TE - 403, com temperatura de $30{ }^{\circ} \mathrm{C}$ durante 5 dias. As análises foram realizadas em triplicata para cada condição em estudo.

Cabe salientar que, para evitar o efeito dos solventes no desenvolvimento fúngico, estes foram evaporados em rotaevaporador e ressuspensos em água nos casos de obtenção dos extratos com metanol e acetato de etila.

Durante o desenvolvimento dos fungos, foram efetuadas medições ortogonais dos diâmetros das colônias no $3^{\circ}$ e $5^{\circ}$ dia de incubação. A inibição foi avaliada pelo crescimento do diâmetro e pela observação visual do crescimento do micélio, comparada com placas controle (DEL RÍO et al., 2003; NGUEFACK et al., 2004).

A porcentagem de inibição fúngica foi calculada de acordo com a Equação 1:

$\mathrm{I}=100 *(\mathrm{C}-\mathrm{T}) / \mathrm{C}$

em que: $\mathrm{I}=$ Porcentagem de inibição, $\mathrm{C}=$ Medida do diâmetro de crescimento do fungo no meio controle e $\mathrm{T}=$ Medida do diâmetro de crescimento do fungo no meio contendo o extrato. 
Também foi calculada e expressa a porcentagem de inibição do crescimento fúngico por $\mu \mathrm{g}$ de composto fenólico total, considerando-se os diferentes teores de compostos fenólicos totais nas matrizes (OLIVEIRA; BADIALE-FURLONG, 2008).

\subsection{Análise estatística}

Foi realizada análise de variância (ANOVA), sendo que as médias das triplicatas dos compostos fenólicos e do teste de atividade antifúngica foram comparadas entre si pelo teste de Tukey, ao nível de 5\% de significância.

\section{Resultados e discussão}

\subsection{Caracterização das amostras}

A acidez da maioria dos vegetais, geralmente confere proteção suplementar contra a contaminação por microrganismos provenientes do solo, pó ou insetos.

Entre os vegetais estudados nenhum pode ser considerado de elevada acidez, visto que o teor de acidez da cebola, em porcentagem de ácido pirúvico, foi de $0,36 \%$ e $\mathrm{pH} 5,16$; do farelo de arroz foi de $0,1 \%$ e pH 6,1; e da microalga Chlorella phyrenoidosa foi de $0,2 \%$ e pH 5,7, ou seja, em nenhuma das matrizes estudadas a acidez foi superior a 0,5\%. Desta forma, dificilmente o teor de ácidos potencialmente ionizáveis poderia estar associado a propriedades antifúngicas ou conservadoras (BECKMAN, 2000).

No método adaptado para determinação de compostos fenólicos, o limite de detecção foi de $38 \mu \mathrm{g}$ de fenol, a recuperação média do método foi de $92 \%$, o coeficiente de variação de $6,1 \%$ e os resultados das determinações aparecem na Tabela 1.

A Tabela 1 apresenta o conteúdo fenólico total nos extratos de cebola nos três solventes (média), de farelo de arroz e da microalga Chlorella phyrenoidosa.

O conteúdo de fenóis totais variou entre $0,077 \mathrm{mg} \cdot \mathrm{g}_{(\mathrm{bs})}^{-1} \mathrm{em}$ extrato acetoetílico e $2,833 \mathrm{mg} \cdot \mathrm{g}_{(\mathrm{bs})}^{-1}$ em extrato aquoso de cebola. A variabilidade na distribuição e composição dos compostos fenólicos é grande para os diferentes tecidos estudados neste trabalho, bem como vem sendo mencionado por outros autores. Estes teores podem ser influenciados, como o de todos os outros componentes, pela variedade, espécie, procedimento de plantio, condições de estocagem e processo industrial ao qual o tecido é submetido (KIM; JEONG; LEE, 2003).

Comparativamente a outros materiais mencionados pela literatura, como funcionais pelo seu conteúdo fenólico, como banana $0,31 \mathrm{mg}_{\text {fenóis }} \cdot \mathrm{g}^{-1}$ amostra, maçã 1,0 mg.g-1 e batata

Tabela 1. Conteúdo dos fenóis totais presentes nos extratos estudados.

\begin{tabular}{lc}
\hline Extrato & Fenóis Totais $\left(\mathrm{mg}^{\left.-g^{-1}{ }_{(\mathrm{bs})}\right)}\right.$ \\
\hline${ }^{\star}$ Cebola (metanol) & 2,274 \\
${ }^{\star}$ Cebola (água) & 2,833 \\
${ }^{\star}$ Cebola (acetato de etila) & 0,077 \\
Farelo de arroz & 0,522 \\
Chlorella phyrenoidosa & 0,202 \\
\hline
\end{tabular}

${ }^{\star}$ Cebola seca até $11 \%$ de umidade.
0,99 $\mathrm{mg} \cdot \mathrm{g}^{-1}$ (equivalente de tirosina); 0,061-0,084 mg.g-1 (ácido ferúlico) em bagaço de laranja (ZHOU et al., 2004) e $0,35 \mathrm{mg} \cdot \mathrm{g}^{-1}$ em polpa de berinjela (BADIALE-FURLONG et al., 2003), a cebola e o farelo de arroz parecem ser bastante promissores como aporte de fenólicos na dieta.

Os solventes que propiciaram a extração de maiores teores de compostos fenólicos da cebola foram a água e o metanol, demonstrando que estes são abundantes nesta matriz e indicam a presença de flavonoides, pois estes, caracteristicamente, são bastante solúveis nestes solventes. Nos extratos obtidos com acetato de etila, os valores indicam baixas concentrações de fenóis polimerizados.

\subsection{Atividade antifúngica}

Para estudos de compostos antifúngicos em tecidos de origem vegetal, são utilizadas ervas medicinais, especiarias (orégano, cravo, canela e pimenta) e outras plantas comestíveis ou não. Os resultados têm mostrado que extratos e óleos essenciais de cebola, alho e outros vegetais de uso na dieta da população tem potencial para inibir o desenvolvimento de fungos (BENKEBLIA, 2004; OLIVEIRA; BADIALE-FURLONG, 2008; SOUZA et al., 2004; YIN; TSAO, 1999). No caso deste estudo, a cebola foi considerada, pela sua riqueza em compostos fenólicos e disponibilidade local e nacional, a valores comerciais pouco compensadores aos produtores. O farelo de arroz foi um subproduto escolhido para estudo a partir dos resultados promissores de Oliveira e Badiale-Furlong (2008) com extratos de grãos de arroz com atividade antifúngica considerável. A microalga Chlorella phyrenoidosa foi considerada a partir de informes da literatura sobre seu conteúdo de compostos funcionais diversos.

Os diâmetros das colônias do fungo Rhyzopus oryzae nos meios de cultura contendo os extratos em estudo aparecem na Tabela 2, especificando os resultados do $3^{\circ}$ e $5^{\circ}$ dia de incubação.

Nenhum dos extratos exerceu inibição total sobre o Rhyzopus oryzae., mesmo aumentando os níveis de extrato fenólicos adicionados ao meio de crescimento, o que sugere que estes extratos precisariam ser mais concentrados para inibir esta espécie fúngica.

Segundo a literatura, os grupos hidroxílicos presentes nos compostos fenólicos podem formar pontes de hidrogênio com enzimas do metabolismo microbiano desativando-as e inibindo o desenvolvimento da biomassa fúngica (JUGLAL; GOVINDEN; ODHAV, 2002; PORTE; GODOY, 2001).

Ao relacionar a medida do diâmetro de crescimento da colônia com o conteúdo fenólico dos extratos de cebola em metanol e acetato de etila e de farelo de arroz, foi verificado que estes promoveram uma redução na velocidade de crescimento do Rhyzopus oryzae, quando as concentrações no meio foram respectivamente superiores a 77; 2,3 e $35 \mu \mathrm{g}_{\text {fenóis }} \cdot \mathrm{mL}_{\text {meio }}^{-1}$.

$\mathrm{Na}$ Tabela 3 estão os resultados da porcentagem de inibição. $\mu \mathrm{g}_{\text {fenol total }}^{-1}$ contra o fungo Rhyzopus oryzae em presença dos extratos fenólicos da cebola, farelo de arroz e Chlorella phyrenoidosa no $3^{\circ}$ e $5^{\circ}$ dia de incubação. 
Tabela 2. Diâmetros médios de crescimento do Rhyzopus oryzae em presença dos extratos de fenólicos de cebola, farelo de arroz e Chlorella phyrenoidosa.

\begin{tabular}{|c|c|c|c|}
\hline \multirow[t]{2}{*}{ Extratos } & \multirow{2}{*}{$\begin{array}{l}\text { Concentração de } \\
\text { fenóis no meio } \\
\mu \mathrm{g}_{\text {fenóis }} \mathrm{mL}^{-1}\end{array}$} & \multicolumn{2}{|c|}{$\begin{array}{l}\text { Diâmetro da } \\
\text { colônia }(\mathrm{cm})\end{array}$} \\
\hline & & $3^{\circ}$ dia & $5^{\circ}$ dia \\
\hline \multirow{3}{*}{$\begin{array}{l}\text { Cebola } \\
\text { (extrato metanólico) }\end{array}$} & 70 & $8,0^{\mathrm{a}}$ & $8,5^{\mathrm{a}}$ \\
\hline & 77 & $4,4^{\mathrm{b}}$ & $8,5^{\mathrm{a}}$ \\
\hline & 86 & $2,1^{\mathrm{b}}$ & $5,3^{\mathrm{b}}$ \\
\hline \multirow{3}{*}{$\begin{array}{l}\text { Cebola } \\
\text { (extrato acetoetílico) }\end{array}$} & 2,0 & $8,5^{\mathrm{a}}$ & $8,5^{\mathrm{a}}$ \\
\hline & 2,3 & $6,0^{\mathrm{b}}$ & $8,5^{\mathrm{a}}$ \\
\hline & 2,6 & $4,1^{\mathrm{b}}$ & $6,0^{\mathrm{b}}$ \\
\hline \multirow{3}{*}{$\begin{array}{l}\text { Cebola } \\
\text { (extrato aquoso) }\end{array}$} & 120 & $8,5^{\mathrm{a}}$ & $8,5^{\mathrm{a}}$ \\
\hline & 150 & $8,5^{\mathrm{a}}$ & $8,5^{\mathrm{a}}$ \\
\hline & 185 & $8,5^{\mathrm{a}}$ & $8,5^{\mathrm{a}}$ \\
\hline \multirow{3}{*}{$\begin{array}{l}\text { Farelo de arroz } \\
\text { (extrato metanólico) }\end{array}$} & 28 & $8,5^{\mathrm{a}}$ & $8,5^{\mathrm{a}}$ \\
\hline & 35 & $7,7^{\mathrm{a}}$ & $8,5^{\mathrm{a}}$ \\
\hline & 46 & $3,6^{\mathrm{b}}$ & $7,1^{\mathrm{a}}$ \\
\hline \multirow{3}{*}{$\begin{array}{l}\text { Chlorella } \\
\text { (extrato metanólico) }\end{array}$} & 3,0 & $8,5^{\mathrm{a}}$ & $8,5^{\mathrm{a}}$ \\
\hline & 3,3 & $8,5^{\mathrm{a}}$ & $8,5^{\mathrm{a}}$ \\
\hline & 3,7 & $8,5^{\mathrm{a}}$ & $8,5^{\mathrm{a}}$ \\
\hline Controle (água destilada) & - & 8,5 & 8,5 \\
\hline
\end{tabular}

Médias seguidas pela mesma letra não diferem estatisticamente pelo Teste de Tukey ao nível de confiança de $95 \%$ em relação ao controle.

Tabela 3. Inibição fúngica contra Rhyzopus oryzae em presença dos extratos fenólicos de cebola, farelo de arroz e Chlorella phyrenoidosa.

\begin{tabular}{|c|c|c|c|}
\hline \multirow[t]{2}{*}{ Extratos } & \multirow{2}{*}{$\begin{array}{l}\text { Concentração de } \\
\text { fenóis no meio } \\
\mu g_{\text {fenóis }} \mathrm{mL}^{-1}\end{array}$} & \multicolumn{2}{|c|}{ \%inibição. $\mu \mathrm{g}_{\text {fenol total }}^{-1}$} \\
\hline & & $3^{\circ}$ dia & $5^{\circ}$ dia \\
\hline \multirow{3}{*}{$\begin{array}{l}\text { Cebola } \\
\text { (extrato metanólico) }\end{array}$} & 70 & 0,084 & 0 \\
\hline & 77 & 0,147 & 0 \\
\hline & 86 & 0,875 & 0,368 \\
\hline \multirow{3}{*}{$\begin{array}{l}\text { Cebola } \\
\text { (extrato acetoetílico) }\end{array}$} & 2,0 & 0 & 0 \\
\hline & 2,3 & 12,8 & 0 \\
\hline & 2,6 & 19,9 & 11,3 \\
\hline \multirow{3}{*}{$\begin{array}{l}\text { Cebola } \\
\text { (extrato aquoso) }\end{array}$} & 120 & 0 & 0 \\
\hline & 150 & 0 & 0 \\
\hline & 185 & 0 & 0 \\
\hline \multirow{3}{*}{$\begin{array}{l}\text { Farelo de arroz } \\
\text { (extrato metanólico) }\end{array}$} & 28 & 0 & 0 \\
\hline & 35 & 0,268 & 0 \\
\hline & 46 & 1,25 & 0,358 \\
\hline \multirow{4}{*}{$\begin{array}{l}\text { Chlorella } \\
\text { (extrato metanólico) }\end{array}$} & 3,0 & 0 & 0 \\
\hline & 3,3 & 0 & 0 \\
\hline & 3,7 & 0 & 0 \\
\hline & - & & \\
\hline
\end{tabular}

Os resultados referentes à adição dos extratos metanólicos e acetoetílicos de cebola e metanólico de farelo de arroz ao meio de cultura demonstraram uma tendência de prevenir o desenvolvimento micelial do fungo Rhyzopus oryzae, sendo que o extrato acetoetílico de cebola apresentou a maior porcentagem de inibição fúngica. Os extratos aquosos de cebola e metanólico de Chlorella phyrenoidosa não se mostraram eficazes para a inibição do Rhyzopus oryzae.
Conforme dados de literatura e o observado neste trabalho, a inibição fúngica não está relacionada com a concentração dos fenóis nos extratos, demonstrado pelo efeito do extrato aquoso de cebola, que, apesar de possuir concentração de compostos fenólicos até 60 vezes superior aos demais, não inibiu o desenvolvimento do halo das colônias em todo o período de incubação.

O acompanhamento do crescimento das colônias em presença dos extratos de cebola extraída nos três sistemas solventes, do farelo de arroz e da Chlorella phyrenoidosa, medidas no $3^{\circ} \mathrm{e} 5^{\circ}$ dia de incubação está ilustrado na Figura 1. Nos conjuntos de fotos apresentados na Figura 1, os controles aparecem acima e abaixo, da esquerda para a direita as concentrações são crescentes, sendo 1a) os extratos metanólicos de cebola, 1b) os extratos aquosos de cebola, 1c) o extrato acetoetílico de cebola, 1d) o extrato metanólico de farelo de arroz e 1e) o extrato metanólico de Chlorella phyrenoidosa.

A Figura 1 assim como os dados da Tabela 3, permitiu verificar uma acentuada diferença no desenvolvimento das hifas nos extratos metanólicos, acetoetílico da cebola e no extrato de farelo de arrozà medida que foram sendo adicionadas em maiores concentrações aos meios de cultura. Nos extratos aquosos de cebola e metanólico de Chlorella phyrenoidosa, não foi observada a inibição do crescimento fúngico em nenhuma das condições testadas. Isto sugere que, para inibir o desenvolvimento de Rhyzopus oryzae, abundante em algumas matrizes, estes extratos, como foram obtidos, não foram eficientes, embora fosse observado macroscopicamente menor desenvolvimento de hifas. O microrganismo apresenta acentuado desenvolvimento em hifas que dificultam o acompanhamento do crescimento do halo por longos períodos, em vista disto foram estimadas as inibições específicas para facilitar a identificação do extrato com maior potencial de inibição fúngica, em um intervalo curto de experimento adequado para triagem.

A Figura 1, também permite perceber claramente a tendência de que, ao aumentar a concentração de extratos metanólicos e acetoetílicos de cebola e metanólicos de farelo de arroz, ocorreu uma diminuição do halo de desenvolvimento fúngico decorrente da concentração destes tipos de compostos fenólicos. Resultados semelhantes foram obtidos por Pereira et al. (2006), Chalfoun et al. (2004), Velluti et al. (2003, 2004), que também salientaram que este comportamento requer um estudo específico, pois fatores tais como: substrato e reação do microrganismo ao substrato e diferentes tipos de compostos podem interferir sobre o comportamento dos fungos.

O teste de Diferença de Médias (DMS) mostrou que no $3^{\circ}$ e $5^{\circ}$ dia de incubação a inibição ocasionada pelos extratos aquosos, em todas as concentrações utilizadas $(120 ; 150$ e $\left.185 \mu \mathrm{g}_{\text {fenóis }} \cdot \mathrm{mL}^{-1}\right)$ e os demais extratos nas menores concentrações utilizadas, não foi significativa em relação ao controle. Foram observadas diferenças significativas no intervalo de $95 \%$ de confiança entre as médias dos diâmetros de crescimento no $3^{\circ}$ e $5^{\circ}$ dia de incubação com relação ao controle quando as concentrações foram $86 \mu \mathrm{g}$ fenóis $\mathrm{mL}^{-1}(\mathrm{p}=0,031)$ para extrato metanólico de cebola e $2,6 \mu \mathrm{g}_{\text {fenóis }} \cdot \mathrm{mL}^{-1}(\mathrm{p}=0,015)$ para o extrato acetoetílico de cebola. 

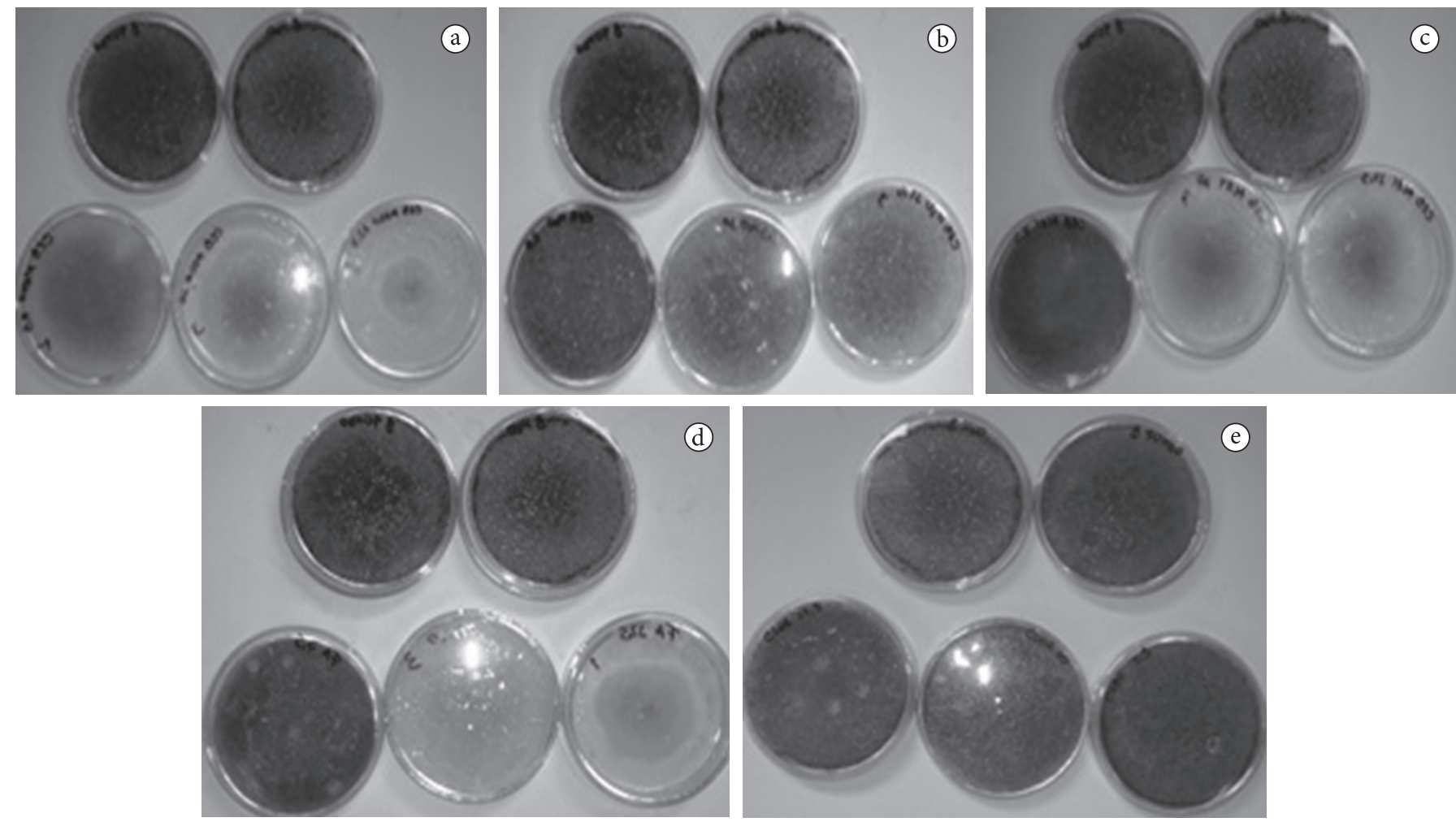

Figura 1. Halos de crescimento fúngico nos meios contendo: a) extrato metanólico de cebola; b) cebola aquoso; c) cebola acetoetílico; d) farelo de arroz metanólico; e e) Chlorella phyrenoidosa metanólico.

Pereira et al. (2006), estudando o efeito da adição do óleo essencial de cebola sobre o desenvolvimento micelial dos fungos Aspergillus flavus e Fusarium sp., verificaram que não havia inibição fúngica nas concentrações de 500 a $2000 \mathrm{mg} \cdot \mathrm{mL}^{-1}$ de meio, o que sugere que o óleo essencial não contém os compostos com atividade antifúngica. Os resultados encontrados mostram que os extratos de compostos fenólicos fixos obtidos de cebola são mais eficientes na inibição fúngica que os óleos essenciais, pois apresentaram inibição em concentrações até 5000 vezes menores.

\section{Conclusões}

Os extratos da cebola extraídos com os diferentes solventes continham uma faixa ampla de compostos fenólicos totais variando entre 0,077 e 2,833 mg.g $\mathrm{g}_{(\mathrm{bs})}^{-1}$. Nos extratos de Chlorella phyrenoidosa e de farelo de arroz, a faixa de variação nos teores fenólicos foi mais estreita, entre 0,202 e $0,522 \mathrm{mg}$ fenóis ${ }^{-1} \cdot{ }_{(b s)}^{-1}$ amostra, respectivamente.

O teste de atividade antifúngica em ágar diluído mostrou que os extratos fenólicos da cebola extraídos com metanol e acetato de etila e o extrato de farelo de arroz apresentaram atividade antifúngica sobre o fungo Rhyzopus oryzae, atingindo, no $5^{\circ}$ dia 38,30 e $17 \%$ de inibição para o extrato metanólico de cebola, acetoetílico de cebola e metanólico de farelo de arroz, respectivamente. Os extratos aquosos de cebola e metanólico de Chlorella phyrenoidosa não apresentaram atividade antifúngica contra o fungo testado.

\section{Agradecimentos}

Os autores agradecem ao CNPq e à Capes as bolsas de estudo concedidas ao primeiro e ao segundo autor, à EMATERRS a doação das cebolas e ao IRGA o farelo de arroz.

\section{Referências bibliográficas}

ASSOCIATION OF OFFICIAL ANALYTICAL CHEMISTS AOAC. Official Methods of Analysis. Horwitz, W. (Ed.). $17^{\text {th }}$ ed. Gaithersburg, 2000. CD-ROM.

BADIALE-FURLONG, E. et al. Avaliação do potencial de compostos fenólicos em tecidos vegetais. Vetor, n. 13, p. 105-114, 2003.

BAKAN, B. et al. Possible role of Plant Phenolics in the Production of Trichothecenes by Fusarium graminearum strains on different Fractions of Maize Kernels. Journal and Agricultural Food Chemistry, n. 51, p. 2826-2831, 2003.

BECKMAN, C. H. Phenolic-storing cells: keys to programmed cell death and periderm formation in wilt disease resistance and in general defense responses in plants? Physiological and Molecular Plant Pathology, n. 57, p. 101-110, 2000.

BENKEBLIA, N. Antimicrobial activity of essential oil extracts of various onions (Allium cepa) and (Allium sativum). LebensmittelWissenschaft und-Technologie, n. 37, p. 263-268, 2004.

BRUL, S.; KLIS, F. M. Mechanistic and Mathematical Inactivation studies of food spoilage fungi. Fungal Genetics and Biology, n. 27, p. 199-208, 1999.

CHALFOUN, S. M. et al. Effect of powdered spice treatments growth, sporulation and production of aflatoxin by toxigenic fungi. Ciência e Agrotecnologia, v. 28, n. 4, p. 856-862, 2004. 
COLLA, L. M.; BADIALE-FURLONG, E.; COSTA, J. A. V. Antioxidant properties of Spirulina (Arthospira) platensis cultivated under different temperatures and nitrogen regimes. Brazilian archives of biology and technology, v. 50, n. 1, p. 161-167, 2007.

CONAB: Produção e consumo no Brasil de arroz. Disponível em: <http://www.conab.gov.br/download/safra $>$. Acesso em: 8 jan. 2008.

DEL RÍO, J. A. et al. Enhancement of phenolic compounds in olive plants (Olea europaea L.) and their influence on resistance against Phytophthora sp. Food Chemistry, n. 83, p. 75-78, 2003.

DERNER, R. B. et al. Microalgas, Produtos e Aplicações. Ciência Rural, v. 36, n. 6, p. 1959-1967, 2006.

EMATER/RS: Classificação Comercial da Cebola. Disponível em: <http://www.emater.tche.br>Acesso em: 6 dez. 2007.

GRIFFIN, D. H. Fungal Physiology. 2. ed. [S.l.]: [s.n.], 1994. 458 p.

JUGLAL, S.; GOVINDEN, R.; ODHAV, B. Spice oils for the control of co-occurring micotoxin-producing fungi. Journal of Food Protection, v. 65, n. 4, p. 683-687, 2002.

KIM, D. O.; JEONG, S. W.; LEE, C. Y. Antioxidant capacity of phenolic phytochemicals from various cultivars of plums. Food Chemistry, n. 81, p. 321-326, 2003.

LIMA, V. L. A. G. et al. Fenólicos totais e atividade antioxidante do extrato aquoso de broto de feijão-mungo (vignaradiatal). Revista Nutrição, v. 17, n. 1, p. 53-57, 2004.

MELO, E. A.; GUERRA, N. B. Ação antioxidante de compostos fenólicos naturalmente presentes em alimentos. Boletim da Sociedade Brasileira de Ciência e Tecnologia de Alimentos, n. 36, p. 1-11, 2002.

NGUEFACK, J. et al. Evaluation of five essential oils from aromatic plants of Cameroon for controlling food spoilage and mycotoxin producing fungi. International Journal of Food Microbiology, n. 94, p. 329-334, 2004.
OLIVEIRA, M. S.; BADIALE-FURLONG, E. Screening of antifungal and antimycotoxigenic activity of plant phenolic extracts. World Mycotoxin Journal, v. 1, n. 2, p. 1-10, 2008.

PEREIRA, M. C. et al. Inibição do desenvolvimento fúngico através da utilização de óleos essenciais de condimentos. Ciência e Agrotecnologia, v. 30, n. 4, p. 731-738, 2006.

PORTE, A.; GODOY, R. L. O. Alecrim (Rosmarinus officinallis L.): Propriedades antimicrobiana e química do óleo essencial. Boletim Centro de Pesquisa de Processamento de Alimentos, v. 19, n. 2, p. 193-210, 2001.

RASOOLI, I.; ABYANEH, M. R. Inhibitory effects of thyme oils on growth and aflatoxin production by Aspergillus parasiticus. Food Control, n. 15, p. 479-483, 2004.

SOUSA, C, M. et al. Fenóis totais e atividade antioxidante de cinco plantas medicinais. Química Nova, v. 30, n. 2, p. 351-355, 2007.

SOUZA, S. M. C. et al. Avaliação de óleos essenciais de condimentos sobre o desenvolvimento micelial de fungos associados a produtos de panificação. Ciência e Agrotecnologia, v. 28, n. 3, p. 685-690, 2004.

VELLUTI, A. et al. Initial screening for inhibitory activity of essential oils on growth of Fusarium verticillioides, F. proliferatum and $F$. graminearum on maize-based agar media. Food Microbiology, v. 21, p. 649-656, 2004.

VELUTTI, A. et al. Inhibitory effect of cinnamon, clove. lemongrass, oregano and palmarose essential oils on growth and fumonisin B1 production by Fusarium proliferatum in maize grain. International Journal of Food Microbiology, n. 89, p. 145-154, 2003.

YIN, M. C.; TSAO, S. M. Inhibitory effect of seven Allium plants upon three Aspergillus species. Journal of food microbiology, n. 49, p. 49-56, 1999.

ZHOU, Z. et al. The distribution of phenolic acids in rice. Food Chemistry, n. 87, p. 401-406, 2004. 